\title{
IGUALDADE SUBVERSIVA CONTRA O CINISMO DEMOCRÁTICO LIBERAL
}

\author{
IGUALDAD SUBVERSIVA CONTRA EL CINISMO \\ DEMOCRÁTICO LIBERAL \\ SUBVERSIVE EQUALITY AGAINST LIBERAL \\ DEMOCRATIC CTNICISM
}

\author{
Daniel de Mendonça ${ }^{1}$
}

${ }^{1}$ Universidade Federal de Pelotas/RS, Brasil

RESUMO: O objetivo do artigo é discutir teoricamente a relação entre democracia liberal e desigualdade, na defesa da ideia de que a luta pela igualdade é sempre um profundo e necessário ato de subversão política contra uma estrutura de poder estabelecida. Para a consecução desse objetivo, inicialmente, apresentamos a discussão acerca do fundamento democrático da vontade dos iguais. Na sequência, articulamos a relação entre um sistema político e a necessária exclusão que ele promove. Na seção seguinte, analisamos a ideia da lei como a arbitrariedade. Por fim, propomos, tendo em vista o fundamento democrático da vontade dos iguais, que a lei seja preterida em nome desta vontade, que o sistema jurídico seja um meio de execução da decisão política e não o contrário, como comumente tem ocorrido nas democracias ocidentais.

PALAVRAS-CHAVE: Democracia; Igualdade; Subversão Política; Vontade dos Iguais.

RESUMEN: El objetivo del artículo es discutir teóricamente la relación entre democracia liberal y desigualdad, en la defensa de la idea de que la lucha por la igualdad es siempre un profundo y necesario acto de subversión política contra una estructura de poder establecida. Para la consecución de ese objetivo, inicialmente, presentamos la discusión acerca del fundamento democrático de la voluntad de los iguales. En consecuencia, articulamos la relación entre un sistema político y la necesaria exclusión que promueve. En la sección siguiente, analizamos la idea de la ley como la arbitrariedad. Por último, proponemos, teniendo en cuenta el fundamento democrático de la voluntad de los iguales, que la ley sea preterida en nombre de esta voluntad, que el sistema jurídico sea un medio de ejecución de la decisión política y no lo contrario, como comúnmente ha ocurrido en las democracias occidentales.

PALABRAS CLAVE: Democracia; Igualdad; Subversión Política; La Voluntad de los Iguales.

ABSTRACT: This aim of this article is to theoretically discuss the relation between liberal democracy and inequality, by defending the idea that the struggle for equality is always a profound and necessary political subversive act against an established power structure. For this, initially, we present a discussion on the democratic foundation of the will of equals. After that, we articulate the relationship between a political system and the necessary exclusion that it promotes. Next, we analyze the idea of the law as arbitrary. Finally we propose, according to the democratic foundation of the will of equals, that the law has to be overlooked in the name of such will, that the legal system be just a mean of the execution of the political decision and not the opposite, as commonly has occurred in West democracies.

KEYWORDS: Democracy; Equality; Political Subversion; the Will of Equals. 


\section{Introdução}

O objetivo deste texto é discutir teoricamente a relação entre democracia liberal e desigualdade, na defesa da ideia de que a luta pela igualdade é sempre um profundo e necessário ato de subversão política contra uma estrutura de poder estabelecida. A análise concentra-se ainda na crítica do uso do sistema jurídico como ferramenta política para barrar ou, ao menos, protelar a efetividade de direitos. É neste exato momento que a fórmula do "cinismo democrático-liberal" entra em cena: "sabemos que eles têm direitos, mas também sabemos que temos a lei do nosso lado". Nossa proposta para combater a estratégia do uso da lei para retardar ou até mesmo impedir o avanço efetivo dos direitos conquistados está, como desenvolveremos nas páginas que seguem, no abandono da primazia da norma jurídica em detrimento da política democrática fundada naquilo que chamaremos de a "vontade dos iguais".

Para a consecução do objetivo central do artigo, ele está organizado da seguinte forma. Inicialmente, apresentamos a discussão acerca do fundamento democrático da vontade dos iguais. Veremos ainda, nesta primeira parte, que, em sendo a vontade dos iguais um significante flutuante, ou seja, um significante em disputa por discursos antagônicos (Laclau, 2013), toda tentativa de cristalização de significados será, em última análise, sempre ineficaz ao mesmo tempo que requerida constantemente. Neste ponto, a ideologia, como a negação da finitude de uma experiência (Laclau, 1993), tem lugar, seja no momento de apresentar-se como o suporte simbólico da criação de uma alternativa política, seja ainda quando promove a sua naturalização no sentido de negar a sua contingência.

Na sequência, articularemos a relação entre um sistema político e a necessária exclusão que ele promove. Toda denúncia em nome da vontade dos iguais fundamenta-se em exclusões sistêmicas. Essa discussão é preparatória à seção seguinte, a qual analisará que a lei - entendida como o sistema jurídico do Estado de Direito nas democracias liberais representativas - quando percebida como um fim em si do regime e não um mero meio para a promoção de direitos conquistados, torna-se um verdadeiro empecilho para a consecução da vontade dos iguais. Assim, a lei, que deveria ser um mecanismo de inclusão, funciona como forma de exclusão, de espécie paralisante, que une comodismo e cinismo, comportamentos próprios das democracias ocidentais.

$\mathrm{Na}$ seção seguinte, analisaremos a ideia da lei como a arbitrariedade. Arbitrariedade no sentido de que toda norma é fruto de uma decisão política tomada num terreno indecidível, ou seja, em que outras decisões poderiam ter tido lugar mas não tiveram, pois foram arbitrariamente negadas, derrotadas na luta político-simbólica de imposição de um sentido entendido como verdadeiro. Dessa forma, toda decisão política é artificial e, portanto, passível de ser constantemente revisada.

Por fim, proporemos, tendo em vista o fundamento democrático da vontade dos iguais, que a lei seja preterida em nome desta vontade, que o sistema jurídico seja um meio de execução da decisão política e não o contrário (o seu fim), como comumente ocorre nas democracias ocidentais. 


\section{Democracia como vontade dos iguais e a totalização ideológica}

Partamos da ideia de que a “igualdade é o fundamento do discurso democrático”. Entendemos não ser nenhuma novidade uma afirmação como esta, visto que, por exemplo, Platão deixa claro - ainda que como parte de sua posição antidemocrática - que a forma de governo democrática "dispensa uma espécie de igualdade, tanto ao que é desigual como ao que é igual" (Platão, 2000, p. 275). Contemporaneamente e de modo semelhante, valendo-se da análise que faz de Aristóteles, Rancière afirma:

O povo nada mais é que a massa indiferenciada daqueles que não têm nenhum título positivo - nem riqueza, nem virtude - mas que, no entanto, têm reconhecida a mesma liberdade que aqueles que os possuem. A gente do povo é de fato simplesmente livre como os outros. Ora, é dessa simples identidade com aqueles que, por outro lado, lhes são em tudo superiores que eles tiram um título específico. O demos atribui-se, como sua parcela própria, a igualdade que pertence a todos os cidadãos. E, com isso, essa parte que não é parte identifica sua propriedade imprópria com o princípio exclusivo da comunidade, e identifica seu nome - o nome da massa indistinta dos homens sem qualidade - com o nome da própria comunidade. (Rancière, 1996, pp. 23-24)

É bem verdade que tanto para Platão (2000) quanto para Aristóteles (1955), a assunção da liberdade, antes da igualdade, é o que caracteriza a democracia. No entanto, a liberdade só pode existir - está implícito no discurso desses filósofos - quando baseada em algo que lhe antecede, ou seja, a igualdade. Nesse sentido, só podem ser livres aqueles que não estão sob o domínio dos outros, somente são livres os iguais. Tanto liberdade quanto igualdade, portanto, são indispensáveis à democracia e necessariamente "extensivas a todos os indivíduos independentemente de suas condições”. O demos, ou seja, os pobres, que não são nem oligoi (ricos) nem aristoi (melhores), tornam-se iguais e tão livres, mesmo sendo "inferiores": a "democracia, assim, suspende a diferença, criando politicamente a igualdade”. Uma criação radical, que cancela unilateralmente a distinção "natural" entre os homens.

Isso quer dizer que fora da democracia toda igualdade é seletiva; são iguais, na oligarquia, os ricos, são iguais, na aristocracia, os melhores. É somente no governo do demos que a igualdade é universal e de fato igualitária. Dessa forma, ela não é um atributo transcendental ou propriamente humano, mas uma condição política radicalmente instituída "na" e "pela" democracia. Democracia "não" como um regime político específico, unívoco e historicamente desenvolvido, mas como um princípio aplicado a todos dos governos populares fundados e refundados ao longo de diversas experiências que atravessam o tempo histórico, desde os precursores gregos do século quinto anterior à era cristã.

Reafirmamos: democracia não tem uma relação necessária com uma forma específica de governo, mas com uma ideia, um princípio, uma episteme. A democracia não é a lei, não pode ser restrita à lei e nem sequer estar a serviço da lei: "ela é a vontade dos iguais", seja qual for esta vontade, estapafúrdia ou não. Democracia é um certo status, artificialmente criado, como todo produto da política: o status da igualdade de todos os diferentes antes de qualquer coisa. A partir daí, erige-se o resto. Numa frase: "a igualdade é o fundamento da democracia”. Fundamento é o que se diz essencialmente do que é, como se encontrássemos o núcleo duro de algo. Para a democracia, a igualdade é este fundamento. No entanto, não 
é simplesmente uma igualdade por si só, mas uma igualdade para expressar uma vontade, para manifestar um desejo que apenas a política é capaz de prometer o seu cumprimento.

Para os antigos, como vimos, a democracia põe juntos, e de forma artificial, os naturalmente desiguais, os ricos, os melhores e os sem qualquer qualidade. Notemos, então, que, de forma privada ou antes da pólis, os homens têm atributos que os diferenciam num sentido mais ou menos pejorativo, uma espécie de classificação natural que eterniza a desigualdade, muito mais do que a simples diferença. A política democrática é a suspensão temporária desse estado natural e a outorga que torna iguais os que mereciam, mas também aqueles que não mereciam serem considerados iguais.

Outro capítulo decisivo na história da democracia vem muitos séculos depois da aventura grega clássica. Trata-se da assunção radicalmente diversa daquela dos antigos, pois que atribuía a igualdade natural dos homens como produto de um pensamento burguês e liberal reinante na Inglaterra do século XVII. A ideia de que a vida em sociedade deveria ser forjada a partir de um contrato - um novo acordo artificial - dar-se-ia justamente para manter os homens na comunidade política como já se encontravam em estado de natureza: iguais. Nenhum indivíduo era naturalmente mais rico, suficientemente mais forte ou mais inteligente do que os demais (Hobbes e Locke, como amplamente conhecido, já claramente afirmavam ser esta a condição dos homens em estado de natureza). Isso não significava, é claro, que a afirmação dessa igualdade fosse a da simplificação do mundo em uma monolítica e inverídica igualdade do tipo $\mathrm{A}=\mathrm{A}$, mas uma mais interessante e realista, ou seja, $\mathrm{A}$ $=\mathrm{B}$, o que significava que mesmo sendo A diferente de B, ainda sendo um homem diferente de outro homem, isso não poderia significar que um devesse ter mais direitos do que o outro como resultado de uma natureza que os desigualava. Simplificando: a diferença natural entre os homens, para o liberalismo político, não deveria ser vista como produtora de uma desigualdade natural, mas, ao contrário, esta diferença não seria suficiente para hierarquizar os homens no estado de natureza. O resultado mais radical dessa nova condição humana provavelmente foi a execução do rei francês no século seguinte, mas também todas as revoluções que se seguiram à francesa, revoluções cujo fundamento era o democrático: o da defesa da vontade dos iguais.

A vontade dos iguais como fundamento da democracia é um significante que flutua sem estar ligado a qualquer significado preciso. Lacan já dizia que “todo significante real é, como tal, um significante que nada significa” (Stavrakakis, 1999, p. 26). Neste sentido, no contex to deste artigo, a assunção do fundamento democrático ser a vontade dos iguais não tem um significado preciso, justamente para que ela possa ser diferentemente significada. Em nome desse fundamento foram justificadas revoluções liberais, revoltas anarquistas, revoluções socialistas, mobilizações populistas, entre outras. Isto quer dizer que entre a ideia da igualdade como fundamento da democracia e a aplicação deste fundamento nas diversas experiências reconhecidas como democráticas existe um claro desnível estrutural ou a operação de dois níveis distintos.

O primeiro deles é o nível do fundamento, do significante que nada significa precisamente e que redunda no enunciado "democracia como a vontade dos iguais". O outro nível é o da tentativa de aplicação desse fundamento, quando são atribuídos significados mais ou menos precisos, mais ou menos específicos à ideia de democracia como vontade dos iguais. É por isso que discursos ideologicamente diferentes operam com os mesmos significantes, atribuindo a eles distintos significados. Esta é a razão que explica ser a igualdade um termo presente seja no discurso socialista, seja no liberal: o mesmo signi- 
ficante com significados diversos. Vejamos mais adiante as consequências da aplicação prática do fundamento democrático.

No segundo nível, são produzidos dois fenômenos: o da "criação" e o da "naturalização". "Criação" de possibilidades significativas, de formas mais ou menos novas para alcançar a vontade dos iguais em regimes democráticos realmente existentes: representação, participação direta, espaços deliberativos etc. "Naturalização" dessas possibilidades, ou seja, a sempre inútil, constante e necessária tentativa de cristalizar a democracia em uma experiência (por exemplo, reduzir a ideia da democracia como vontade dos iguais à democracia representativa liberal). O momento da naturalização é o tempo da tentativa tornar eterno o que é transitório, de fazer necessário o que não passa de uma contingência. Em ambos os fenômenos (criação e naturalização) opera um processo ideológico, a busca pelo fechamento de sentidos, de anulação de outras possibilidades, enfim, o esforço de significar pela última e definitiva vez a democracia como vontade dos iguais.

Isto quer dizer que "uma” alternativa política entre outras não se coloca simplesmente como "uma" alternativa, mas como a "única" alternativa. Está presente, portanto, a busca de fixação de sentidos baseada numa ideia de verdade, no desvelamento do mundo. Evidentemente que esta verdade é sempre uma verdade distorcida para que outras verdades igualmente distorcidas sejam também possíveis. Sendo a vontade dos iguais um significante sem um significado preciso, como dissemos acima, todas as tentativas de significar o fundamento democrático serão ideológicas neste sentido muito preciso: anunciam-se negando a sua própria finitude. É fundamental, no entanto, não incorrermos no erro de que a ideologia do fechamento é meramente um efeito ilusório. Pelo contrário: toda crença é materialmente constitutiva. Neste sentido, Žižek afirma:

Esta é provavelmente a dimensão fundamental da "ideologia”: a ideologia não é simplesmente uma "falsa consciência", uma representação ilusória da realidade, pois que a realidade já deve ser concebida como "ideológica” ... "Ideológica" não é a "falsa consciência" de um ser (social), mas este ser, na medida em que ele está amparado pela "falsa consciência". (Žižek, 2005, pp. 46-47, grifos do original)

A ideologia sustenta uma realidade, uma forma de vida. Neste sentido, ela alcança uma verdade (ainda que uma verdade particular que, como todas as demais, visa à universalização/hegemonização, a partir do processo de naturalização e da imposição do medo de que fora dela tudo será a barbárie e o caos). Tal verdade, quando hegemônica, constitui-se, por exemplo, numa ordem política, religiosa, moral etc. Assim, não há efetivamente uma verdade sobre a verdade ou, sendo mais específico, não há uma verdade em termos sociais que transcenda à sua própria condição histórica de existência. Como tal, a ideologia é uma fantasia, mas que tem como objeto a construção de uma dada realidade. Poderíamos dizer que a realidade é a nossa própria fantasia. A seguinte passagem de Žižek é exemplar neste sentido: “[o] nível fundamental da ideologia, no entanto, não é o de uma ilusão que mascara o estado real das coisas, senão o de uma fantasia (inconsciente) que estrutura a nossa própria realidade social” (Žižek, 2005, p. 61).

Apesar da tentativa de um regime democrático específico fechar ideologicamente seus sentidos, visando à naturalização de uma certa ordem, esta será sempre precária e contingente. A razão é estrutural, como veremos a seguir. Todo sistema somente pode operar no interior dos seus limites, e esses limites, por definição, são excludentes. É somente a partir 
da exclusão que podemos pensar na vontade, no desejo irrealizado dos iguais. Vejamos como se dá esta operação sistêmica na seção seguinte.

\section{Sistema político e exclusão}

Recuperemos a ideia central desenvolvida na seção anterior, qual seja, a afirmação de que a democracia é a vontade dos iguais. Deve também restar claro que este é o fundamento a partir do qual todos os sistemas políticos democráticos se assentam, mas é também a mesma razão pela qual todos os sujeitos subversivos democráticos são mobilizados contra o regime político (democrático ou não) vigente. Aqui surge um problema político por excelência: o que significa lutar pela democracia como a vontade dos iguais no contexto de um regime fundado neste mesmo fundamento? O que significa ser mais democrático do que o próprio regime democrático instituído?

Nossa resposta simples e direta é a seguinte: toda luta por igualdade é um ato necessário de subversão. Subversão contra certa estrutura de poder que, exatamente no momento em que proclama o reconhecimento de um novo acréscimo de igualdade, de forma lógica e subliminar, impõe também um ponto de desigualdade. Nesse sentido, não há igualdade sem desigualdade: todo sistema político necessariamente inclui e exclui e, consequentemente, não faz o menor sentido falarmos em “inclusão universal”.

Toda estrutura é sempre uma estrutura de exclusão, tendo em vista a óbvia ideia de que a mesma opera somente no interior dos seus limites, os quais são demarcados pela presença de um exterior, sempre negativo. Pensemos, por exemplo, na ideia de democracia num sentido minimalista-liberal. Um Estado recebe o status de democrático quando o seu sistema político articula instituições, tais como "direitos individuais", "liberdade de expressão", "eleições limpas e frequentes", "liberdade de imprensa", "liberdade de associação e de participação em partidos políticos", "igualdade civil”, "respeito ao império da lei" etc. Outras instituições podem ser adicionadas a esta enumeração, mas chegará um momento em que este sistema alcançará o seu limite, ou seja, outros elementos necessariamente ficarão de fora justamente para que se possa considerar a existência deste sistema. Assim, por exemplo, não podem ser articulados nesta plataforma democrática sentidos tais como "restrição à liberdade de expressão", "desigualdades fundadas em questões étnicas, religiosas", "fim do processo eleitoral". Tais sentidos negativos são fáceis de serem enumerados e tornam compreensível a exclusão que estamos tratando que se, por um lado, individualiza o sistema democrático liberal, por outro lado, demonstra que o que não é este sistema é necessariamente negativo. Afinal, qual pensamento progressista hoje defenderia alguma restrição à liberdade de expressão, ao fỉm das eleições e às desigualdades a partir de pressupostos étnicos e religiosos?

Mas se pensássemos na articulação entre democracia liberal e a promoção da igualdade econômica entre os cidadãos na mesma medida em que comumente tem-se buscado igualar civilmente esses mesmos sujeitos? A resposta liberal seria positiva em termos gerais, ou seja, "em tese" não seria visto como negativo um esforço como este; porém, colocá-lo em prática resultaria, sem dúvida, entrar em choque com outros princípios políticos e econômicos muito mais caros ao liberalismo, tais como, por exemplo, o direito individual à propriedade.

O ponto aqui não é exatamente fazer um arrazoado do que faz o liberalismo político, obviamente associado ao desenvolvimento do capitalismo, ser um sistema desigual, mas 
dizer algo mais geral: todo e qualquer sistema é excedente, e temos de considerar a exclusão como uma condição para a produção sistêmica e não uma situação a ser superada por esse mesmo sistema. Tal afirmação é tão óbvia - ou seja, um sistema somente pode operar no interior dos seus limites - ao mesmo tempo em que é frequentemente negligenciada. Neste sentido, toda decisão política é sempre uma eleição para dizer o que está dentro, mas inevitavelmente também para afirmar o que está fora de um sistema. As escolhas verdadeiramente políticas são sempre conflitivas, contingentes, precárias e nunca transcendentes ao sistema que lhes dá suporte.

Afirmar a existência de verdades transcendentes, no sentido de que tenham validade aqui ou em qualquer outro lugar, neste e em outros tempos, significa admitir a possibilidade da existência de significados precisos e não negociáveis desde o seu estabelecimento (em nossos termos: significa dizer que chegamos ao fechamento completo dos sentidos do fundamento democrático aqui discutido). Vejamos, por exemplo, a ideia de que as decisões públicas devam ser necessariamente baseadas numa racionalidade comunicativa, como o que é defendido pela democracia deliberativa habermasiana (Habermas, 2003). Num ambiente acadêmico, local por excelência do uso da razão científica, pode parecer uma alternativa interessante que todas as discussões ocorram a partir de bases racionais; todos ou quase todos estão preparados para usar esse recurso de produção de argumentos e decisões baseadas nesta racionalidade específica. No entanto, uma discussão nestes termos não necessariamente é a melhor alternativa para todos os ambientes sociais. Numa assembleia em um bairro popular, outras formas de argumentação (a partir do exemplo ou da experiência) são tão ou até mesmo mais importantes do que o debate deliberativo. Isso quer dizer que, em termos gerais, não é possível - tampouco desejável - a existência de verdades transcendentes ao meio no qual as mesmas são produzidas. Por que a alternativa discursiva acadêmica seria melhor em todos os demais espaços de deliberação? Todas as verdades produzidas são resultado de decisões ambientadas em condições muito específicas e que servem para esses sistemas e não necessariamente para outros. Assim, a defesa de uma verdade transcendente necessariamente gerará duas alternativas não excludentes entre si: ou estamos diante de uma ingenuidade por parte de quem a defende ou, o que é ainda pior, estamos às portas da totalização da verdade e da morte da política, entendida como momento de decisão entre alternativas que são sempre conflitivas e baseadas em vontades específicas.

Insistimos que, além de toda decisão política ser marcada pela contingência, ela é sempre excludente. Isto quer dizer que não há identidade política que não tenha sido constituída sem a presença da ameaça e da negatividade. Neste caso, por exemplo, um discurso que articula a luta das mulheres contra a opressão machista num contex to social específico, marca antagonicamente as lógicas da inclusão e da exclusão. Se existe uma luta como essa é porque existe, sistemicamente, a exclusão provocada pelo machismo e tolerada pelo sistema social. Temos claro, assim, que o par exclusão/inclusão "indecente" do sistema político tomado em termos institucionais: este é inerradicável. Isso quer dizer que não é a engenharia política o que irá determinar ou não a inclusão efetiva de um direito, mas estruturas muito mais profundas e enraizadas nas relações de poder e de cultura existentes.

É preciso abdicar da ideia de uma sociedade finalmente reconciliada onde inexistirão relações de poder e de exclusão. Sem exclusão não podemos sequer pensar na ideia da política, visto que a primeira é pressuposto da existência da segunda. A questão fundamental não é, portanto, excluir a exclusão em sentido geral, visto ser impossível, mas excluir determinadas formas de exclusão que são significadas como negativas aos sistemas político e social. $\mathrm{Na}$ 
próxima seção, analisaremos o fundamento democrático aplicado à democracia representativa liberal e o triunfo da lei sobre a vontade dos iguais e o seu princípio de exclusão.

\section{Democracia liberal, lei, exclusão e cinismo}

O julgamento axiológico sobre o que incluir e o que excluir em determinada ordem depende inexoravelmente do sistema político no qual este tribunal valorativo tem lugar. Se não há um bem ou um mal transcendente em relação ao tempo e ao espaço, qualquer coisa pode, em tese, representar o bem ou o mal. Por exemplo, há até pouco mais de duzentos anos, a publicização do sofrimento e do suplício de um condenado era cena cotidiana promovida pelo Estado como parte do processo punitivo e de manutenção da ordem pública (Foucault, 1987). Por mais absurdo que possa parecer, um recuo como esse em relação aos direitos sociais e individuais já conquistados, por mais seguros que possamos estar diante dos direitos e dos valores fundamentais de hoje, "avanços" ou "recuos" sociais dependem de sistemas político, social e cultural específicos com vigências sempre contingentes e precárias.

Também devemos desconfiar dos bem-intencionados e de suas "boas intenções" políticas. É abundante a retórica em nome da paz, dos direitos humanos, dos direitos das minorias, entre outros. Em favor dessas boas causas - que inequivocamente são boas num sentido abstrato - perpetra-se justamente o seu contrário. Em prol da defesa dos direitos humanos, países são invadidos; em nome dos direitos das minorias, outras são atacada; em nome da paz, faz-se justamente a guerra. Assim, dizer-se defensor das boas causas não quer dizer a rigor absolutamente nada.

Tal desconfiança aplica-se certamente também em relação aos intransigentes defensores da democracia. Democracia aqui tem nome e sobrenome: democracia liberal representativa. É justamente por ela que se promove o dantesco espetáculo do cinismo político e acadêmico no Ocidente. Neste sentido, esta versão ocidental sobrevive a partir de suas ameaças que projetam cenários catastróficos se esse sistema político for suplantado: reativamente reforça-se, o tempo todo, que além dele tudo será ou a barbárie ou o totalitarismo. A democracia representativa tem claramente a tarefa de naturalizar/sedimentar a sua experiência singular como sendo o próprio fundamento da democracia como a vontade dos iguais. Autoafirma-se defensora da liberdade, da igualdade e de todos os seus derivados políticos e econômicos, quando sabemos que nem uma nem outra são atributos bem partilhados entre os seus cidadãos.

Assim, mesmo admitindo ser a democracia liberal propensa à manutenção de desigualdades (o que, de resto, parece ser uma concordância, ainda que tácita, entre as correntes democráticas radicais), há um sentimento comum que, ainda assim, esse regime é o melhor ambiente para demandar políticas de inclusão. Tal ideia hegemônica articulou, por exemplo, toda a sorte de lutas e de resistências na América Latina, nas décadas de 1970 e 1980, em nome de processos de transição de regimes autoritários para democráticos. Acreditava-se que, com a democracia liberal, seria possível caminhar na direção de novos direitos, sociais e civis, que patentemente eram negados pelas ordens autoritárias, por excelência, restritivas de direitos.

É inegável que houve sensível avanço na obtenção de direitos nos ambientes democrático-liberais na América Latina, em particular no Brasil. No entanto, é linguagem comum 
creditarem-se tais avanços à existência da democracia em si, como se a mesma tivesse a magia ou o poder do reconhecimento de diferenças. Nesse sentido, bastaria o regime ser democrático que a inclusão seria ao menos facilitada quando, de fato, todos os avanços sociais e políticos ocorrem não pela mera existência desse regime, mas, antes e fundamentalmente, pelas lutas articuladas "na" democracia por identidades excluídas de direitos.

Desta forma, a democracia liberal tem um histórico de notórias exclusões e de inclusões de direitos que antes eram vistos como demandas subversivas ao regime. Liberdade de informação, liberdade de expressão, sufrágio universal, entre outros, são institutos "não" democrático-liberais em si, mas incorporados "pela" democracia liberal nos séculos XIX e XX, a partir de lutas políticas como, por exemplo, o direito ao voto feminino, hoje uma obviedade no Ocidente.

Um dos grandes problemas enfrentados nos dias de hoje é o conformismo em relação ao modelo democrático liberal, motivado tendo em vista a praticamente inexistência de alternativas políticas capazes de ameaçar a sua hegemonia. Tal fato é justamente aquele que permite com que os liberais de direita, mas também aqueles de "esquerda", já domesticados com a ideia de uma única via, façam previsões catastróficas contra todo o pensamento crítico a esse modelo. Slavoj Žižek percebe claramente essa estratégia que visa calar toda e qualquer alternativa pós-liberal de democracia:

a noção de totalitarismo, longe de ser um conceito teórico efetivo, é uma espécie de subterfúgio que, em lugar de nos permitir pensar e de nos obrigar a adquirir uma nova visão da realidade histórica que descreve, nos desonera do dever de pensar e, inclusive, impede-nos ativamente que pensemos... Desde o momento em que nos aparece a mais ligeira inclinação de fazer parte de projetos políticos que pretendem se opor seriamente à ordem existente, a resposta é imediata: "Por bem intencionada que seja, acabará necessariamente em um novo Gulag!”. (Žižek, 2002, pp. 13-14, grifos do original)

Para além do conformismo do liberalismo, trataremos de outro aspecto central do regime em questão. Neste sentido, a democracia hegemônica Ocidental prefere o "império da lei" ao "império da vontade dos iguais" ou do povo: a ela não somente falta o demos; esta falta é inclusive desejada. E aqui o ponto não é simplesmente afirmar que a lei (com a sua atribuída impessoalidade) é soberana em último caso em relação à vontade dos iguais, mas algo ainda mais grave: não raras vezes a lei (entendida aqui sempre na sua relação com o sistema jurídico) é a arma utilizada contra a decisão política tomada justamente para evitar a sua implementação.

As ciências humanas e sociais têm normalmente preocupação teórica em relação aos "direitos a serem conquistados", mas uma preocupação reduzida com o cumprimento efetivo daquilo que já foi formalmente conquistado e tido como "justo" e "certo" num contexto social específico. Ademais, entendemos haver certa leniência entre políticos e teóricos sobre o efetivo cumprimento de uma lei que tem como objetivo final produzir um direito. Muitas vezes a única alternativa colocada é a seguinte: - “cumpra-se a lei!” No entanto, nem sempre ela é cumprida, visto que o seu fiel cumprimento depende de uma série de constrangimentos legais, administrativos, políticos que tornam, não raras vezes, a mesma inviável. Gera-se a seguinte situação: tem-se a lei, mas isso não redunda na efetividade do direito. O descumprimento de uma lei após uma ferrenha luta de um movimento social para conquistá-la é literalmente uma vitória de Pirro. 
Parte-se muitas vezes do pressuposto ingênuo de que as democracias representativas liberais assentam suas bases no fiel cumprimento da lei e esta última é a via para a promoção de todo e qualquer direito. Em tese, é assim mesmo que funciona: a lei é vista como meio e não como fim. O problema reside fundamentalmente no desrespeito do que é positivamente valorado, ou seja, há a lei e o seu não cumprimento. No entanto, o descumprimento ocorre principalmente tendo em vista ser o sistema jurídico burocratizado e leniente com situações de desigualdade. O sistema jurídico é alheio ao fiel cumprimento de um direito, pois ele é tautológico: o sistema jurídico tem preocupação com a sua própria sustentação, e o pecado capital do liberalismo está em transferir a política para a esfera jurídica. No liberalismo democrático, o sistema legal passa a ser o fim e não meramente o meio para a efetividade do direito.

Como exemplo da preferência da lei sobre o direito, pensemos numa demanda específica de um movimento social, qualquer uma. Quando a mesma surge, o que se busca é assegurar, "de forma substantiva" e, portanto, não eufêmica, a efetividade de um direito. Sejamos ainda mais diretos e imaginemos uma reivindicação de casas populares articulada por moradores de uma área de risco entre muitas das que existem nas cidades brasileiras. A demanda, digamos, ganha importância, e a municipalidade promete a remoção das pessoas para um local em que as mesmas tenham, além de moradia digna, a garantia do uso de equipamentos urbanos, saneamento básico etc. O tempo passa e, mesmo com a promessa do poder público, a realocação entra numa interminável tramitação de processos e de expedientes administrativos nas esferas municipal, estadual e até federal, o que faz com que o direito substantivo passe a ser preterido para que seja cumprida uma burocracia atroz, sempre em nome da lei.

Toda e qualquer reclamação da comunidade diante da demora excessiva por parte do poder público será respondida com o ardil do respeito à lei, a partir da célebre expressão "lei é lei". Assim, o direito não é efetivamente um direito, mas a colocação de uma peça na engrenagem do sistema legal e burocratizado do Estado. Isso gera a seguinte situação: temos direito a ter direito, mas, não raras vezes, não temos o direito em si, pois as violações ao mesmo são constantes e vistas de forma desdenhosa pelo próprio Estado.

Nesses termos, o recurso à abstração da lei é uma engenhosa forma, entre outras, com que a democracia liberal mantém o statu quo de desigualdade, ainda que a igualdade tenha sido assegurada na letra da lei. Isso quer dizer que convivemos diariamente com o "cinismo democrático-liberal". A fórmula do "cinismo democrático" é a mesma da "razão cínica”, de Peter Sloterdijk (1987), resgatada por Slavoj Žižek (1990, p. 59): "eles sabem muito bem o que estão fazendo, mas mesmo assim o fazem”. Um caricatural exemplo do "cinismo democrático" é a afirmação de que todos os cidadãos têm liberdade de expressão quando sabemos que a imprensa está nas mãos de poderosos conglomerados midiáticos. Do nosso exemplo hipotético sobre o reassentamento urbano da comunidade: "sabemos que eles têm o direito à moradia, mas também sabemos que isso levará um tempo, pois o direito deles está adstrito ao fiel cumprimento da lei”.

O cinismo da democracia liberal nos coloca numa incômoda situação. Ao mesmo tempo em que presenciamos diuturnamente direitos não sendo levados a sério, somos forçados a admitir que os mesmos estão legalmente previstos e que, para garanti-los, existem ainda os meios legais para demandá-los. Assim, vivemos sob o império da lei, mas imersos constantemente em situações profundamente injustas e desiguais, que legalmente postergam o efetivo cumprimento de uma conquista. Dessa forma, o cinismo democrático paralisa 
muitas vezes a própria luta pelo aprofundamento dos direitos, visto que os mesmos, "legalmente”, “já existem”. Se eles existem legalmente, mas são, na prática, desrespeitados ou postergados, eles realmente existem? É evidente que não. O problema não está na lei em si, mas no princípio do jurídico estar acima da vontade dos iguais, da vontade do povo. A lei, não raras vezes, é o refúgio do cinismo e do imobilismo. Cumprir a lei é, muitas vezes, a própria condição da perpetuação de uma injustiça.

\section{Toda lei é uma arbitrariedade}

Apesar do que dissemos sobre a lei, não podemos considerar estranha a sua defesa, mesmo daquela que, percebida socialmente como manifestamente injusta, mereça ser reformada ou ainda revogada. Uma das principais razões para que se defenda uma lei está além de seu conteúdo específico: essa encontra-se, antes, na ideia de lei como estabilização de uma ordem, de uma rotina social.

Um dos sentidos mais fortes da ideia geral de lei está no fato de que, em sendo uma lei, estamos diante de uma necessidade, ou seja, de "uma impossibilidade (ou improbabilidade) de que a coisa aconteça de outra forma” (Abbagnano, 2000, p. 601). O império da necessidade aqui aludido, é claro, refere-se às leis físicas ou naturais; assim, é impossível (ou improvável) que a lei da gravidade falhe ou que o sol deixe de nascer e de se pôr diariamente etc. Uma lei, neste sentido, é uma verdade incontestável, salvo pela ocorrência de um evento desestabilizador que inviabilize a sua constância ou a sua própria ocorrência (daí a ressalva filosófica do "improvável”).

É claro que quando estamos diante de uma lei no âmbito do social não podemos considerá-la no mesmo patamar de necessidade das leis físicas e naturais. Tal foi a constatação um tanto desalentadora de Montesquieu, no século XVIII, quando afirmou que faltava muito para o mundo inteligente ser tão bem gover nado como o mundo físico, "pois ainda que o mundo inteligente possua também leis que por sua natureza são invariáveis, não as segue constantemente, como o mundo físico segue as suas" (Montesquieu, 2005, p. 38). Mesmo assim, o advento das ciências sociais, no século seguinte, tinha entre os seus proeminentes precursores, tais como Comte, Durkheim (e por que não Marx?), o desejo de encontrar leis sociais inelutáveis capazes de explicar e de, com isso, controlar as ações das sociedades humanas.

Tal desejo positivista de encontrar leis necessárias para a organização comunitária foi há muito superado com o desenvolvimento das ciências humanas e sociais em geral durante o século XX. Isso quer dizer que uma lei obviamente "não" é o resultado de uma descrição inequívoca da realidade que ela busca explicar e prever. Uma lei é uma interpretação entre tantas outras possíveis. É parte de um processo ligado ao sistema jurídico como um todo e, portanto, sujeita às regras desse sistema, o que está muito além de uma simples interpretação de um fato e da geração de uma norma correspondente. Mais ainda, e ainda mais importante: toda lei social é o resultado de uma "decisão política". Uma decisão radical, no sentido de que a sua artificialidade redunda também na negação de outras possibilidades dadas no contexto do seu surgimento. A lei, portanto, é análoga à arbitrariedade do signo saussuriano:

O laço que une o significante ao significado é arbitrário ou então, visto que entendemos por signo o total resultante da associação de um significante com um significado, podemos dizer mais simplesmente: "o signo linguístico é arbitrário". 
Assim, a ideia de "mar" não está ligada por relação alguma interior à sequência de sons "m-a-r" que lhe serve de significante; poderia ser representada igualmente bem por outra sequência, não importa qual; como prova, temos as diferenças entre as línguas e a própria existência de línguas diferentes: o significado da palavra francesa boeuf (boi) tem por significante $b-\ddot{o}-f$ de um lado da fronteira francogermânica, e $o-k$-s (Ochs) do outro. (Saussure, 2006, pp. 81-82)

O paralelo que buscamos fazer entre a arbitrariedade do signo linguístico e a arbitrariedade da lei reside no fato de que, em ambos os casos, estamos diante de estruturas e, como tais, produzem sentidos internamente. Daí o signo linguístico não ser a relação de união entre uma "coisa" e uma "palavra", "mas um conceito e uma imagem acústica" (Saussure, 2006, p. 80). Em nossos termos, não discutimos sobre a "existência" das coisas, mas disputamos sentidos sobre o "ser" dessa existência. Todo sentido atribuído depende de sua estrutura de suporte. No caso de uma lei, sua existência igualmente depende de uma estrutura, de uma constelação de regras que foram instituídas a partir de decisões políticas e não a partir de algo transcendente às mesmas (tal como o recorrente argumento do uso da racionalidade). Por que, por exemplo, o mandato de um presidente da República no Brasil é de quatro anos com a possibilidade de uma única reeleição? Simplesmente pelo fato de que a decisão política foi tomada neste sentido, tendo sido tomada em outros contextos estatais de outra forma. A arbitrariedade da lei não pode significar relativismo, mas a assunção de que uma ordem, uma lei, um sistema de regras não é resultado de uma mera interpretação normativa de um fato, no sentido de ser a única possível.

Retirando, assim, a lei de um patamar "sagrado", sendo ela arbitrária, podemos desafiá-la, desrespeitá-la politicamente. Não se trata aqui de discutir a obviedade da afirmação da mutabilidade das leis sociais. A questão central é "opor uma crítica em relação à defesa da existência intrínseca da relação entre a lei ao fato ao qual ela se refere”. Queremos, em outras palavras, discordar da posição que coloca a lei como a expressão da própria realidade que a partir dela visa-se controlar, como se a lei, em última análise, fosse necessariamente a sua tradução ou descrição.

Partiremos do pressuposto, portanto, que "uma lei pode ser descumprida em nome da vontade dos iguais". Uma lei descumprida sob essa alegação representa uma luta em nome da primazia da decisão política sobre a ordem jurídica. Neste sentido, argumentamos que a política deve produzir o jurídico e não o contrário. Toda ação de descumprimento de uma lei ou de desobediência civil de que estamos falando é correlata à ideia rousseauniana da denúncia do "direito do mais forte”, ou seja, "o mais forte nunca é suficientemente forte para ser sempre o senhor, senão transformando sua força em direito e a obediência em dever" (Rousseau, 1978, p. 25). Uma operação de "desobediência” da lei retira dela a sua necessidade (o seu papel mágico e fantasioso), colocando-a num patamar propriamente político e mundano, ou seja, o de uma decisão marcada pela indecidibilidade, tomada no lugar de outras tantas que poderiam ter sido possíveis.

\section{Considerações finais: contra à lei em nome da vontade dos iguais}

Retomemos alguns elementos essenciais do nosso argumento até aqui. Partimos da ideia da vontade dos iguais como o fundamento da democracia. Democracia, entendemos, não se trata de um regime específico, mas de um horizonte de igualdade que dá suporte a 
todas as experiências efetivas de instituição que levam o nome de democracia. Na comparação entre a democracia como horizonte e a democracia como regime político instituído, a primeira é o fundamento, mas também o estopim para a desordem, para a denúncia da desigualdade; a segunda é o sistema que visa a sua própria conservação e, como todo o sistema, promove inclusões e exclusões, igualdades e desigualdades.

A enunciação do fundamento democrático surge com a percepção da desigualdade produzida pelo sistema político (democrático ou não), em franca contradição com o pressuposto da igualdade. Trata-se de um julgamento ao que está instituído e que certamente ameaça a sua sistematicidade, a sua ordem. Só é possível a contestação democrática visto que a vontade dos iguais é um significante vazio (Laclau, 2011) que, como tal, não alcança a sua última fixação significativa, mas tão somente sentidos precários produzidos de forma contingente.

Tendo em vista a dualidade entre democracia como fundamento e democracia como regime, o que se contesta em relação às democracias liberais representativas não é a existência de lei (não há sistema político sem lei), mas a sua primazia em relação à vontade dos iguais. Não é a lei o fundamento da ordem democrática; este reside na "vontade dos iguais". É somente tal vontade que pode ser verdadeiramente democrática, devendo estar a lei a seu serviço e não servindo como uma barreira para a sua implementação.

A vontade dos iguais é o fundamento propriamente democrático e, como tal, atua, no limite, a partir da excepcionalidade. Sua invocação, neste sentido, aparece como um princípio além de toda lei ou ordem estabelecida: age como um escândalo, um excesso perturbador e antagônico à estrutura de poder. Quando falamos em lei estamos tratando-a no seguinte sentido: não de uma única lei, mas de uma lei imersa num sistema legal que gera a desigualdade, naturalizando e conformando uma experiência política.

Colocar a vontade dos iguais sobre a lei é dar primazia à política e à decisão arbitrária contra uma normalidade jurídica naturalizada que promove a desigualdade. A desigualdade será percebida quando a vontade dos iguais se insurgir, quando esse fundamento elusivo da democracia for acionado, o que representará a denúncia de que o regime de leis se mostra incompatível com a vontade e o desejo do demos.

\section{Referências}

Abbagnano, N. (2000). Dicionário de filosofia. São Paulo: Martins Fontes.

Aristóteles. (1955). A política (4a ed.). São Paulo: Atena Editora.

Foucault, M. (1987). Vigiar e punir: história da violência nas prisões. Petrópolis, RJ: Vozes.

Habermas, J. (2003). Direito e democracia: entre facticidade e validade. Rio de Janeiro: Tempo Brasileiro.

Laclau, E. (1993). Nuevas reflexiones sobre la revolución de nuestro tiempo. Buenos Aires: Nueva Visión.

Laclau, E. (2011). Emancipação e diferença. Rio de Janeiro: EdUERJ.

Laclau, E. (2013). A razão populista. São Paulo: Três Estrelas.

Montesquieu.(2005). O espírito das leis. São Paulo: Nova Cultural.

Platão. (2000). A República. São Paulo: Nova Cultural.

Rancière, J. (1996). O desentendimento. São Paulo: Editora 34. 
Rousseau, J. J. (1978). Do Contrato Social (2 ed.). São Paulo: Abril Cultural.

Saussure, F. (2006). Curso de linguística geral. São Paulo: Editora Cultrix.

Sloterdijk, P. (1987). Critique of cynical reason. Minneapolis, USA: University of Minnesota Press.

Stavrakakis, Y. (1999). Lacan Eे the political. London: Routledge.

Žižek, S. (1990). Eles não sabem o que fazem: o sublime objeto da ideologia. Rio de Janeiro: Jorge Zahar.

Žižek, S. (2002). Quién dijo totalitarismo? Cinco intervenciones sobre el (mal) uso de una noción. Valencia, ESP: Pre-textos.

Žižek, S. (2005). El sublime objeto de la ideologia. Buenos Aires: Siglo XXI.

\section{DANIEL DE MENDONÇA \\ https://orcid.org/OOOO-0002-8920-4709}

Graduado em Ciências Jurídicas e Sociais pela Pontifícia Universidade Católica do Rio Grande do Sul (1997), mestrado (2001) e doutorado (2006) em Ciência Política pela Universidade Federal do Rio Grande do Sul e estágio pós-doutoral em Ideology and Discourse Analysis (2009) na University of Essex. É professor associado na Universidade Federal de Pelotas, RS.

Endereço institucional: UFPel. Departamento de Sociologia e Política. Rua Coronel Alberto Rosa, 154. Centro. 96010-770. Pelotas/RS, Brasil.

E-mail ddmendonca@gmail.com

Submissão em: 30/05/2017

Revisões em: 15/02/2019

Aceite em: 19/02/2019

Financiamento: Programa Pesquisador Gaúcho - PqG, da FAPERGS - Fundação de Amparo à Pesquisa do Estado do Rio Grande do Sul. Edital 02/2017.

Consentimento de uso de imagem: Não se aplica. 